\title{
A DINÂMICA TERRITORIAL DAS GRANDES OBRAS DE INFRAESTRUTURA DESENVOLVIDAS NO AMAPÁ NO ÂMBITO DO PROGRAMA DE ACELERAÇÃO DO CRESCIMENTO ${ }^{1}$
}

\author{
TERRITORIAL DYNAMICS OF THE GREAT INFRASTRUCTURE WORKS \\ DEVELOPED IN AMAPÁ UNDER THE GROWTH ACCELERATION PROGRAM
}

Eduardo Margarit Alfena do Carmo ${ }^{1}$

http://lattes.cnpq.br/9106331944059097

Cleuton Pinto Miranda ${ }^{2}$

http://lattes.cnpq.br/4354921036456998

\section{Celene Cunha Monteiro Antunes Barreira ${ }^{3}$}

http://lattes.cnpq.br/1038300875963340

Recebido em: 11/10/2019

Aceito em: 25/11/2019

\begin{abstract}
RESUMO: O Programa de Aceleração do Crescimento (Pac) foi implantado em 2007 com o objetivo de agregar todas as obras do Governo Federal em uma única plataforma. No Amapá, o Pac implantou novas usinas hidrelétricas, pavimentou rodovias, modernizou e ampliou o porto e o aeroporto, entre outras obras de infraestrutura capazes de gerar a fluidez necessária ao desenvolvimento do capitalismo e, consequentemente, promover o crescimento da economia. Portanto, o objetivo deste artigo é apresentar como o Pac se estrutura enquanto instrumento de ordenamento territorial do Amapá. Para tanto, foi realizado o levantamento bibliográfico e documental capaz de fornecer subsídios à compreensão das políticas territoriais fundantes do processo de ordenamento territorial do Amapá. Como resultado, constatou-se que o Pac representa a consoli-
\end{abstract}

${ }^{1}$ Graduado em Geografia pela Universidade Federal Fluminense - UFF (2010), Mestre em Geografia pela Universidade Federal de Mato Grosso do Sul - UFMS (2012) e Doutor em Geografia pela Universidade Federal de Goiás - UFG (2019). É Professor do Curso de Licenciatura em Geografia do Campus Binacional de Oiapoque, da Universidade Federal do Amapá - UNIFAP, desde 2013. Atua principalmente nas áreas de Geografia Agrária e Análise Regional, ministrando disciplinas na graduação e pós-graduação e realizando pesquisas e publicações sobre a dinâmica socioespacial da Amazônia. E-mail: eduardo.margarit@unifap.br

${ }^{2}$ Graduando em Geografia no Campus Binacional de Oiapoque da Universidade Federal do Amapá (UNIFAP). E-mail: cmmiranda1995@hotmail.com

3 Possui graduação em Geografia pela Universidade Federal de Goiás (1978), mestrado em História pela Universidade Federal de Goiás (1989) e doutorado em Geografia (Geografia Humana) pela Universidade de São Paulo (1997). Atualmente é Professora Titular na Universidade Federal de Goiás no Instituto de Estudos Socioambientais- IESA (20142018). Integra o corpo docente do Programa de Pesquisa e Pós-Graduação em Geografia (doutorado e mestrado) do IESA/UFG. Nessa mesma instituição exerceu as funções acadêmicas de Tutora de PET-Geografia/UFG (1997-2003). Diretora do Instituto de Estudos Sócio-Ambientais (IESA)/UFG (1998-2002 e 2014-2018), Pró-Reitora de Graduação/UFG (2002-2006). Fez parte da equipe de Avaliação da Pós-graduação da CAPES, na área de Geografia entre 2010-2014. Tem experiência em pesquisas na área de Geografia, com ênfase em Análise Regional e Planejamento Urbano e Regional atuando principalmente nos seguintes temas: análise regional, desenvolvimento regional, configuração socioespacial, cerrado, cidade e Regiões Metropolitanas. E-mail: celenemonteiro05@gmail.com 
dação do planejamento regional estratégico da Amazônia, fundado em eixos de integração e desenvolvimento, em que as rodovias se apresentam como eixos fundantes da lógica de circulação e incorporação de terras ao desenvolvimento capitalista. Conclui-se que as redes técnicas são os elementos geradores desta nova lógica de ordenamento territorial, capaz de gerar a fluidez necessário ao desenvolvimento capitalista.

Palavras-chave: Amapá; Infraestrutura; Integração; Redes Técnicas.

\begin{abstract}
The Programa de Aceleração do Crescimento (Pac) was implemented in 2007 with the objective of aggregating all Federal Government works in only one platform. In Amapá, Pac implemented new bydroelectric plants, paved highways, modernized and expanded the port and the airport, among others infrastructure works capable of generating the necessary fluidity for the capitalism development and, consequently, promoting the growth of the economy. Therefore, the aim of this paper is to present how Pac is structured as an instrument of Amapá territorial planning. To this end, was realized a bibliographic and documentary survey capable of providing subsidies to understanding the founding territorial policies of the Amapa territorial planning process. As a result, it was found that the Pac represents the Amazonian strategic regional planning consolidation, based on integration and development axes, in which the highways are establishment axes of the circulation and incorporation into capitalist development logic. It is concluded that the technical networks are the generating elements of this new territorial planning logic, capable of generating the necessary fluidity for capitalist development.
\end{abstract}

Key-words: Amapá; Infrastructure; Integration; Technical Networks.

\title{
INTRODUÇÃO
}

O Pac foi uma iniciativa do segundo mandato do governo Lula (2007) para agregar todas as possíveis obras de infraestrutura do País em uma única plataforma e, desta forma, dar a visibilidade necessária às atividades de seu governo. Desta forma, o Pac acabou por agregar diversos projetos de infraestrutura existentes, provenientes do primeiro mandato de Lula e de mandatos de outros governos - essencialmente do Governo de Fernando Henrique -, à novos projetos de infraestrutura, sob um portfólio unificado capaz de potencializar o valor simbólico dos empreendimentos, de forma que pudesse sustentar os diversos aspectos políticos necessários à atmosfera governamental, como estratégia de superação da crise econômica.

No Amapá o Pac representa a consolidação do planejamento regional estratégico da Amazônia, gerando a fluidez necessária ao desenvolvimento do capitalismo por meio de infraestrutura. A rodovia BR-156 passou a representar o principal eixo de integração territorial pretendido pelo Estado no Amapá, por seu valor estratégico de ligação entre a fronteira e as cidades de Macapá e Santana, importantes núcleos comercial e portuário, respectivamente. Para tanto, a rodovia construída na Ditadura Militar precisava ser asfaltada, para gerar maior fluidez no tráfego. Em seus extremos seria preciso gerar a conectividade, em Oiapoque com a Guiana Francesa, por meio de uma ponte, e em Macapá e Santana com o Brasil e o mundo, por meio de um aparelho portuário e aeroportuário competitivos. Por fim, em toda a sua extensão era preciso instalar os sistemas de telecomunicações e de energia vitais para o desenvolvimento de empreendimentos capitalistas. Estas iniciativas compunham a estrutura básica da estratégia do poder hegemônico para ampliação da carteira de possibilidades de expansão territorial do grande capital no Amapá e passaram a ser sinalizadas como fundamentais para o desenvolvimento econômico do estado, representando um marco no reordenamento territorial do Amapá.

PRACS: Revista Eletrônica de Humanidades do Curso de Ciências Sociais da UNIFAP 
Diante das premissas apresentadas, este artigo tem como objetivo apresentar como o Pac se estrutura enquanto instrumento de ordenamento territorial do Amapá. Para tanto, de início, são analisadas as políticas territoriais predecessoras e suas relações com o Pac. Em seguidas são tecidos comentários sob o contexto político-territorial que estrutura o Pac. Por fim, são identificadas e comentadas as grandes obras de infraestrutura executadas pelo Pac no Amapá e a função destas obras como instrumentos de ordenamento territorial do estado.

As informações e argumentos expostos nesse artigo são fruto de pesquisa realizada no âmbito do doutoramento em Geografia, que se seguem com a colaboração dos coautores que contribuíram na construção da publicação destes resultados. A metodologia que orientou a pesquisa para a análise do recorte específico publicado neste artigo foi baseada no levantamento bibliográfico e documental capaz de fornecer subsídios à compreensão das políticas territoriais fundantes do processo de ordenamento territorial do Amapá.

\section{PRECEDENTES ESTRUTURANTES DA POLÍTICA TERRITORIAL ESTATAL PARA O AMAPÁ}

No tocante à região amazônica, o Estado engendrou, ao longo do último século, mecanismos de anexação territorial à lógica capitalista. Bertha Becker lembra que a fase inicial de planejamento regional da Amazônia ocorre no governo de Getúlio Vargas, com a "Marcha para Oeste", a criação da Fundação Brasil Central, o Programa de Desenvolvimento para a Amazônia, a delimitação da região amazônica por critérios científicos e a criação da Superintendência de Valorização Econômica da Amazônia (SPVEA). Já no governo de Juscelino Kubitschek ocorrem intervenções territoriais do Estado mais significativas na Amazônia, por meio da construção das rodovias Belém-Brasília e Brasília-Acre. Entretanto, apenas durante a Ditadura Militar (1964-1985) é que ocorre o planejamento regional efetivo da Amazônia, por meio de um projeto geopolítico de modernização territorial, que envolveu a implantação de rodovias, sistemas de telecomunicações, desenvolvimento urbano, industrialização, projetos de colonização, migração, incentivos fiscais, concessão de crédito, entre outros (BECKER, 2004).

No Amapá, o desenvolvimento do Programa de Integração Nacional (Pin), criado em 1970, foi responsável pela implantação das rodovias BR-210 e BR-156. Por não terem sido pavimentadas e não possuírem conexão com o restante do País, as rodovias BR-156 e BR210 acabaram por não permitir o pleno desenvolvimento do capitalismo. Neste período também foi inaugurada a Usina Hidrelétrica Coaracy Nunes (1978), no Rio Araguari, que apenas veio a suprir a crescente demanda energética da capital e das atividades de mineração de manganês que eram executadas no Amapá. Apesar de precárias, as redes técnicas implantadas no Amapá durante a Ditadura Militar foram responsáveis por introduzir um esboço da política territorial hegemônica, que passaria a vigorar como imperativo na constituição das demandas do poder público nas décadas seguintes, pautando a melhoria e expansão destas redes técnicas como condição para o desenvolvimento econômico do Amapá.

Com a promulgação da Constituição de 1988 torna-se obrigatório que o Governo Federal elabore um Plano Plurianual (PPA), definindo o conjunto de conceitos, políticas, estratégias, diretrizes de ação e metas para um período de quatro anos. Desta forma, a partir da década de 1990, há uma renovação do planejamento regional estratégico, com foco na inserção na economia mundial. O governo do Presidente Fernando Henrique (1995-2002) desenvolveu 
o PPA 1996-1999 com foco no estimulo da produção e redução de desigualdades regionais e sociais, atribuindo ao PPA o título de "Programa Brasil em Ação". Dando prosseguimento a mesma lógica, o PPA 2000-2003 recebeu o título de "Avança Brasil", tendo como foco um modelo de gestão e desenvolvimento de projetos arrolados por Eixos Nacionais de Integração e Desenvolvimento (Enid) (SILVA, 2012, p. 139-140). Os programas tinham como foco a retomada do crescimento econômico, fundamentado nos objetivos logísticos nacionais dos Enid representados no Mapa 1.

Mapa 1: Eixos Nacionais de Integração e Desenvolvimento

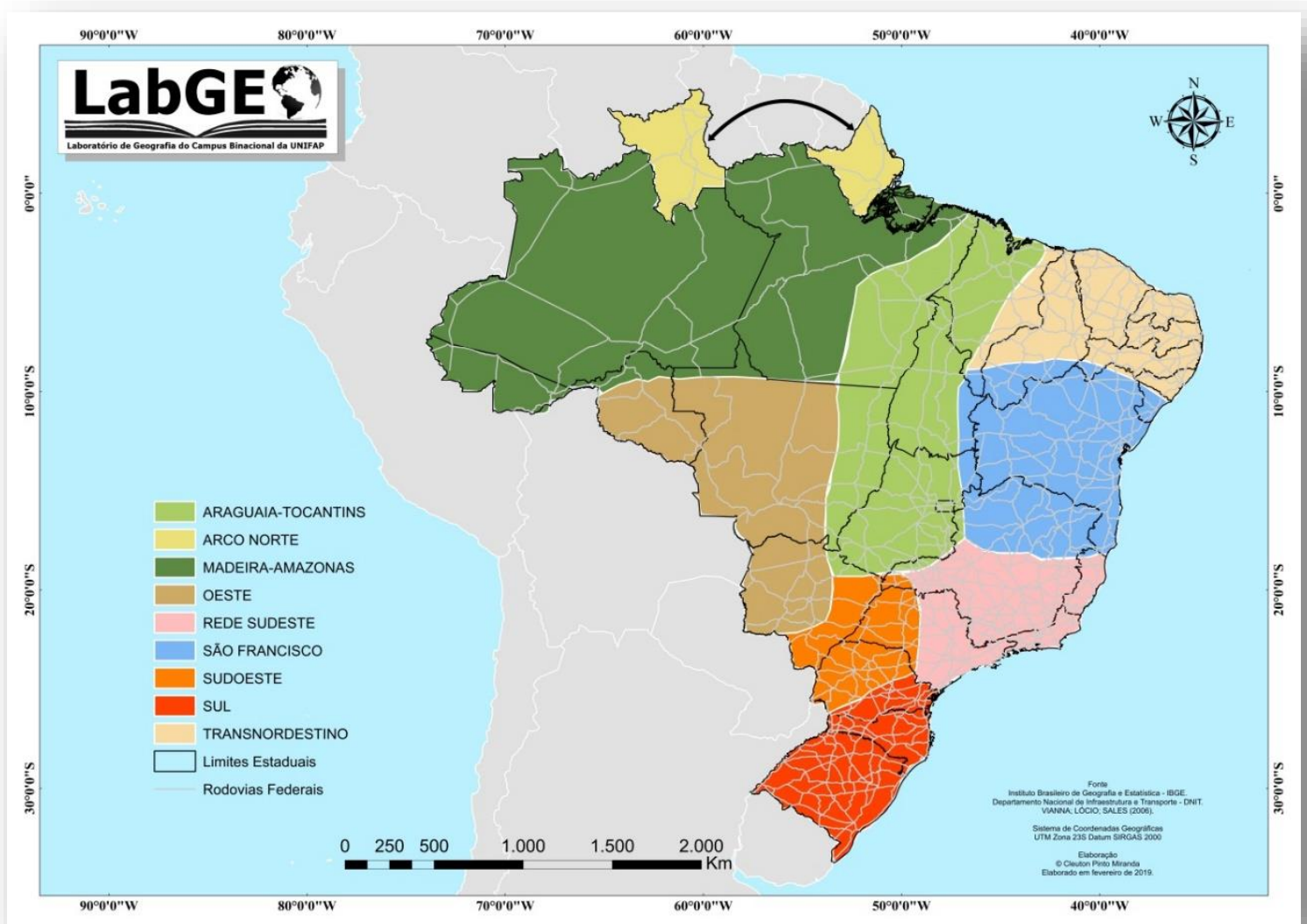

Os Enid transformam o território brasileiro em eixos de fluidez, consorciando unidades espaciais de acordo com a afinidade ou potencialidade dos fluxos estabelecidos entre elas. Mais do que isso, os Enid agregam a competitividade territorial existente ou potencial, convertendo-a para o desenvolvimento capitalista. Com a execução destes programas, Bertha Becker destaca que:

Resgata-se, assim, o modelo exógeno associado ao projeto do vetor tecno-industrial que permanecera arrefecido na década anterior. Este vetor reúne projetos de atores interessados na mobilização de recursos naturais e de negócios, tais como empresas e bancos nacionais e internacionais, e segmentos de governos estaduais, do governo federal e das Forças Armadas (BECKER, 2004, p. 132).

A criação dos Enid, em 1996, dentro do programa Brasil em Ação, inseriu o Amapá no 
"Arco Norte", como forma de promover o desenvolvimento regional, valorizando a integração transfronteiriça entre o Brasil, por meio do Amapá e Roraima, e a Guiana, Suriname e Guiana Francesa. Para tanto, seria necessário pavimentar rodovias, construir pontes nas fronteiras e, enfim, dotar o território das redes técnicas necessárias ao desenvolvimento capitalista, principalmente nos setores de telecomunicações, transporte e energia (BECKER, 2004; SUPERTI, 2013).

Na Amazônia como um todo, os programas Brasil em Ação e Avança Brasil representaram a estratégia de efetivação de políticas territoriais no bojo dos valores neoliberais. Tratava-se de programas pautados em corredores de desenvolvimento, que tinham como estratégia territorial intensificar a fluidez do território e, assim, permitir a maior inserção de cada região nos circuitos produtivos do capitalismo global, reproduzindo, assim, sob uma identidade e bases renovadas, a lógica exógena da política territorial da Ditadura Militar para a Amazônia.

Entre as diferenças da política territorial da Ditadura Militar e a do governo de Fernando Henrique, Eliane Superti destaca que "Diferentemente dos polos de desenvolvimento que haviam marcado a década de 1970 e estimulavam o crescimento polarizado, os eixos priorizavam as redes capazes de promover integração e modernização da infraestrutura econômica comercial em amplas áreas" (SUPERTI, 2013, p. 95). Portanto, a fluidez passa a ser o imperativo de agregação de valor ao território e a questão logística torna-se a dimensão suprema das políticas territoriais do Estado.

A renovação e fortalecimento do programa de corredores de desenvolvimento no Brasil ocorreu por meio do lançamento do projeto Integração das Infraestruturas Regionais SulAmericanas (Iirsa), lançado em 2000, como produto da política externa do Brasil e em complementação aos Enid. O Iirsa é um projeto que agrega doze países da América do Sul na formação de uma estrutura integrada de redes técnicas capazes de dotar o território de maior competitividade no cenário global, conforme detalha Eliane Superti:

Concebida com base no conceito de regionalismo aberto elaborado pela Comissão Econômica para América Latina e Caribe - Cepal na década de 1990, o Iirsa focaliza o continente sulamericano como espaço geoeconômico integrado, onde, para o avanço do crescimento econômico, é preciso reduzir ao mínimo as barreiras internas ao comércio e os estrangulamentos infraestruturais. O Comitê de Coordenação Técnica do Iirsa, reunido em 2003 em Lima, estabeleceu três grandes objetivos: a) apoiar a integração de mercados para melhorar o comércio intrarregional; b) apoiar a consolidação de cadeias produtivas para alcançar competitividade nos grandes mercados mundiais; e c) reduzir o "custo latino-americano" por meio da criação de uma plataforma logística vertebrada e inscrita na economia global (SUPERTI, 2013, p. 100).

O Iirsa coloca o Brasil no centro da infraestrutura logística da América do Sul. O Mapa 2 apresenta os eixos de integração do Iirsa. Seus principais eixos representam a extensão dos domínios das redes técnicas brasileiras, integrando territórios e, ao mesmo tempo, reordenando-os de acordo com a lógica do capitalismo global. Enquanto o Iirsa desponta como elemento de fortalecimento da economia sul-americana, da mesma forma também reproduz a lógica de estruturação da infraestrutura de circulação para exportação, pois o objetivo maior continua sendo o abastecimento dos mercados europeu, norte-americano e asiático com commodities. 
Mapa 2: Integração das Infraestruturas Regionais Sul-Americanas (Iirsa)

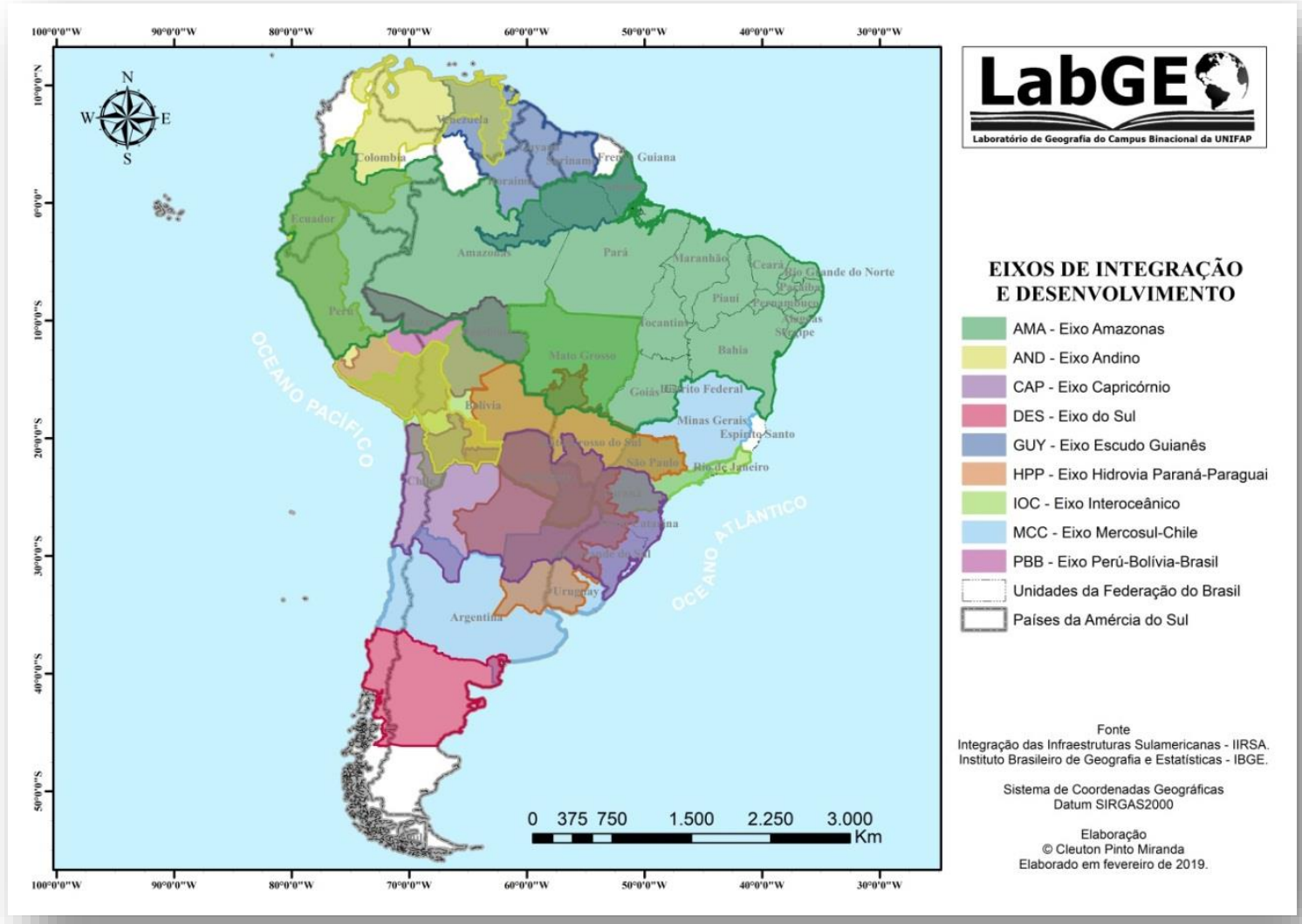

No Amapá, o Eixo do Escudo das Guinas do Iirsa significou a ratificação do Arco Norte como corredor de desenvolvimento e contribuiu para o fortalecimento político do Enid. Entretanto, até o final do mandato de Fernando Henrique (2002), não foram efetivadas as obras necessárias para a consolidação do Arco Norte e, consequentemente, não houve a promoção da fluidez necessária ao desenvolvimento do capitalismo no Amapá. Apesar de não ter se consolidado, o Arco Norte passou a ser a estratégia de integração territorial que ditaria o planejamento territorial do Amapá, vindo a ganhar contorno apenas com as grandes obras de infraestrutura do Pac.

\section{O CONTEXTO DO PAC: ANTIGAS ESTRATÉGIAS SOB NOVA IDENTI- DADE}

A estratégia de desenvolvimento dos Enid e da Iirsa, que concebem a integração territorial na lógica do capitalismo mundial, permaneceu durante o governo do Partido dos Trabalhadores (PT) sob a alcunha de Programa de Aceleração do Crescimento. Portanto, o Pac abarcou a continuidade da política de instituição de eixos de desenvolvimento do governo anterior e tratou de consolidá-la. Sobre este processo de transição das políticas territoriais nas mudanças de governo, Eliane Superti tece uma importante comparação que merece atenção: 
Os PPA do governo FHC eram, assim, portadores de uma diferença importante em relação às políticas territoriais do período anterior. Eles traçavam linhas de intervenção com a pretensão de integrar o País à América do Sul, abrindo mercados do Atlântico ao Pacífico por meio de um sistema de infraestrutura eficiente capaz de garantir competitividade e permitir a exploração de novos espaços para acumulação de capital. As estratégias de integração internacional desenhadas no governo FHC foram incorporadas e aprofundadas no governo Lula e se fizeram presentes no PPA de 2004/2007 e no Programa de Aceleração do Crescimento (PAC) (SUPERTI, 2013, p. 94).

Com a união do conjunto de obras espalhadas pelo território brasileiro em um único e principal programa - o Pac -, a retórica do desenvolvimento da economia ganhou ainda mais força e tempo na grande mídia e discursos do Governo. A grandiosidade do Pac se revelou não só pela magnitude das obras, mas também por todo o aparato econômico, fiscal e jurídico mobilizado pelo programa. Junto às obras de infraestrutura do Pac estavam políticas fiscais e tributárias, para incentivar o desenvolvimento do capitalismo, como estratégia macroeconômica. Para tanto, o Pac passou a integrar três grupos de estratégicas fundamentais:

Uma programação maciça de investimentos em infraestrutura logística (rodovias, ferrovias, portos etc.), geração de energia e infraestrutura social (saneamento e habitação), com grande participação das empresas estatais e bancos públicos;

Um conjunto de incentivos tributários (exonerações fiscais a setores e bens específicos) e financeiros (expansão e redução do custo do crédito para investimento) ao setor privado, complementado por arranjos institucionais voltados para o estabelecimento de regras estáveis e condições de segurança jurídica ao investimento privado na indústria e na infraestrutura;

Um arranjo de compromissos da política fiscal e monetária até 2010 (cujo elemento central é a redução progressiva da taxa básica de juros da economia), tendo em vista viabilizar o financiamento do programa de investimento público (pela, entre outras coisas, redução do superávit primário e da velocidade de crescimento dos gastos com pessoal) e tornar consistente em termos macroeconômicos o programa de crescimento, o dispêndio público e a estabilização de preços (JARDIM e SILVA, 2015, p. 63).

Por meio desta tríade, o Pac criou as condições para o livre desenvolvimento do capitalismo, atraindo e fomentando investimentos privados, que sustentaram o crescimento da economia brasileira durante o governo do PT e permitiram o desenvolvimento de diversos empreendimentos capitalistas.

O principal aspecto político relacionado ao Pac é a mobilização de um gigantesco aparato estatal - instituições e recursos públicos - em torno de uma única chancela - o Pac - que se tornou o símbolo da política econômica e social dos quatro mandatos do governo do PT. Estados e municípios estiveram envolvidos como beneficiários das obras, ou diretamente como executores das mesmas, o que proporcionou a agregação de diversos grupos políticos em torno do Pac. Tal instrumento revelou-se como poderoso mecanismo de manutenção do poder e da governabilidade para o PT. As ações do Pac mantinham a propaganda governamental energicamente ativa na mídia e na opinião pública, gerando uma psicosfera positiva e promovendo a maior popularidade do governo. $\mathrm{Na}$ mesma medida, as obras mobilizavam as elites locais e regionais, que eram beneficiadas como executoras (prefeituras e governos dos estados), usuárias (grande capital), ou construtoras dos empreendimentos.

O Pac foi dividido em duas etapas: Pac 1 (2007-2010), executado no segundo mandato do

PRACS: Revista Eletrônica de Humanidades do Curso de Ciências Sociais da UNIFAP 
governo Lula, e PAC 2 (2011-2018), etapa iniciada no governo da presidente Dilma Rousseff e continuada após seu impeachment. A excelência do Pac se revelou na manutenção de quatro mandatos do governo PT no comando do País. A operação Lava Jato da Polícia Federal, ao revelar esquemas de corrupção envolvendo obras do Pac, desmantelou da mesma forma o próprio Pac e, consequentemente, o governo PT, o que demonstra o peso que o Pac teve na política governamental contemporânea.

$\mathrm{Na}$ Amazônia, o Pac simbolizou a retomada da política territorial que foi gradativamente construída por meio do planejamento regional estratégico desenvolvido ao longo do último século, sob uma nova identidade. Da mesma forma, as políticas territoriais implantadas com o Pac no Amapá são resultantes de um conjunto de políticas territoriais predecessoras, desenvolvidas com o objetivo de integrar a Amazônia aos circuitos produtivos do capitalismo global.

Um dos símbolos da reinvenção do Pac na Amazônia foi a Usina Hidrelétrica de Belo Monte, no rio Xingu, no estado do Pará. A construção de hidrelétricas no rio Xingu havia sido tentada na década de 1980. A Usina Hidrelétrica de Kararaô ${ }^{2}$ seria construída afetando os povos indígenas da região. O empreendimento foi abandonado devido à resistência dos povos indígenas, que ficou eternizada na imagem da indígena Tuíra encostando um facão no rosto de José Antônio Muniz Lopes, presidente da Eletronorte à época (MANCHETE, 1989). O fato repercutiu negativamente na mídia nacional e internacional, o que fez com que o Banco Mundial suspendesse o financiamento ao empreendimento, proporcionando a desistência do Governo Federal brasileiro de construir a usina hidrelétrica no rio Xingu (RAMBO, 2014).

$\mathrm{Na}$ década de 1990 houve novos estudos sobre hidrelétricas no rio Xingu, mas somente com o Pac é que o empreendimento foi retomado. A Usina Hidrelétrica de Belo Monte é fruto de adaptações de projetos executados nas décadas de 1980 e 1990, para reduzir o impacto socioambiental e tornar a obra "mais aceitável". A reinvenção de Kararaô sob o título de Belo Monte é uma demonstração do caráter conservador do Pac, que ressuscitou antigos projetos sob uma nova identidade, para, por fim, reproduzir os velhos ideais do sistema de manutenção da ordem hegemônica.

Maria Chaves Jardim e Márcio Rogério Silva, com base em postulados da sociologia econômica, defendem que o Pac se insere em um cenário que pode ser compreendido como a introdução de um novo desenvolvimentismo, como aquele iniciado no governo de Getúlio Vargas, mas com peculiaridades que o distanciariam do conceito de neodesenvolvimentismo proposto por Luiz Carlos Bresser-Pereira, conforme relatam:

Nossos dados empíricos nos permitem afirmar que o neodesenvolvimentismo presente no governo Lula-Dilma só é comparável com o modelo de desenvolvimento adotado por Vargas, em relação ao retorno do Estado como ator relevante do jogo. O retorno do Estado no governo Lula aconteceu num contexto de crise do modelo de privatização (crise no modelo neoliberal) adotado pelo governo Fernando Henrique Cardoso nos anos 1990. Lembramos que a crise do modelo de privatizações não aconteceu somente no Brasil, mas antes, no país modelo - a Inglaterra, país de onde inclusive surgiram alternativas para contornar os fracassos das privatizações, como as parcerias público-privadas (PPPs), que consideramos a novidade cognitiva do neodesenvolvimentismo dos governos Lula e Dilma.

O modelo adotado por Lula e Dilma vai além da indústria de base e promove a convergências entre diversas pautas, em princípio inegociáveis, como finanças versus inclusão social, altas ta-

PRACS: Revista Eletrônica de Humanidades do Curso de Ciências Sociais da UNIFAP 
xas de juros versus geração de emprego, por exemplo. Assim, sugerimos que essa seria a singularidade do modelo de desenvolvimentismo estabelecido nos governos de Lula e Dilma, e suas distinções com o conceito de neodesenvolvimentismo cunhado por Bresser-Pereira (JARDIM; SILVA, 2015, p. 174-175).

É no comparativo com outras estratégias governamentais de desenvolvimento que o Pac se demonstrou como a perpetuação da heurística clássica do desenvolvimento econômico, estabelecendo bases de novas formas do mesmo modelo patrimonialista que caracteriza o Estado brasileiro.

\section{O PAC NO AMAPÁ}

No Amapá, o processo de integração territorial competitiva por meio das grandes obras de infraestrutura fomenta, da mesma forma, o grande capital. A criação de condições de fluidez do território aliadas à disponibilidade de bens naturais e ao potencial logísticolocalizacional são elementos que agregam competitividade aos empreendimentos capitalistas que resolvam se instalar no Amapá.

No Quadro 1 são apresentados os empreendimentos das categorias de infraestrutura logística e energética previstos no Pac para o Amapá, onde é possível destacar três estratégias básicas do programa: consolidar infraestruturas existentes, como é o caso do asfaltamento de rodovias, ampliar outras, como na construção de novas usinas hidrelétricas e novo terminal de passageiros do aeroporto, e integrar as infraestruturas, como na construção da linha de transmissão e da Ponte Binacional. Vale ressaltar que não foram listados os empreendimentos da categoria de infraestrutura social e urbana, por não ser o foco deste trabalho.

\begin{tabular}{|c|c|c|c|c|}
\hline Tipo & Município & Descrição & $\begin{array}{c}\text { Investimento } \\
\text { previsto } \\
\text { (Mil/R\$) }\end{array}$ & $\begin{array}{l}\text { Estágio da } \\
\text { ação }\end{array}$ \\
\hline Aeroporto & Macapá & $\begin{array}{l}\text { Construção do novo terminal de passageiros e obras } \\
\text { complementares do Aeroporto de Macapá }\end{array}$ & 225.330 & Concluída \\
\hline Aeroporto & Oiapoque & Cerca operacional, sinalização e balizamento noturno & 2.500 & Concluída \\
\hline $\begin{array}{l}\text { Linha de trans- } \\
\text { missão }\end{array}$ & - & Interligação Tucuruí-Macapá-Manaus & 3.400 .000 & Concluída \\
\hline Ponte & Oiapoque & $\begin{array}{l}\text { Construção de ponte internacional sobre o Rio Oia- } \\
\text { poque }\end{array}$ & 115.000 & Concluída \\
\hline Porto & Santana & $\begin{array}{l}\text { Concentrador de Dados e Portal de Informações } \\
\text { Portuárias }\end{array}$ & $153.220^{*}$ & Em execução \\
\hline Porto & Santana & $\begin{array}{l}\text { Programa Federal de Apoio a Regularização e Gestão } \\
\text { Ambiental Portuária - PRGAP }\end{array}$ & - & $\begin{array}{l}\text { Ação prepa- } \\
\text { ratória }\end{array}$ \\
\hline Rodovia & Oiapoque & $\begin{array}{l}\text { Construção dos Acessos e Instalações de Fronteira da } \\
\text { Ponte Internacional }\end{array}$ & 3.000 & Concluída \\
\hline Rodovia & $\begin{array}{l}\text { Pracuúba, Ama- } \\
\text { pá e Calçoene }\end{array}$ & $\begin{array}{l}\text { BR-156/AP Subtrecho Igarapé do Breu - } \\
\text { Calçoene }\end{array}$ & 81.000 & Concluída \\
\hline Rodovia & Calçoene & $\begin{array}{l}\text { BR-156/AP Pavimentação Subtrecho Calçoene - } \\
\text { Oiapoque lote } 1\end{array}$ & 50.000 & Concluída \\
\hline Rodovia & $\begin{array}{l}\text { Calçoene e Oia- } \\
\text { poque }\end{array}$ & $\begin{array}{l}\text { BR-156/AP Pavimentação Subtrecho Calçoene - } \\
\text { Oiapoque lote } 2\end{array}$ & $37.022,279$ & Em execução \\
\hline Rodovia & Oiapoque & $\begin{array}{l}\text { BR-156/AP Pavimentação Subtrecho Calçoene - } \\
\text { Oiapoque lote } 3\end{array}$ & $37.022,279$ & Em execução \\
\hline Rodovia & Oiapoque & $\begin{array}{l}\text { BR-156/AP Pavimentação Subtrecho Calçoene - } \\
\text { Oiapoque lote } 4\end{array}$ & 64.000 & Concluída \\
\hline Rodovia & - & Estudos e projetos & $7.631,461$ & Concluída \\
\hline Rodovia & - & Estudos e projetos & $3.964,104$ & Em execução \\
\hline
\end{tabular}




\begin{tabular}{|l|c|l|c|l|}
\hline Rodovia & - & Estudos e projetos & $-\begin{array}{l}\text { Ação prepa- } \\
\text { ratória }\end{array}$ \\
\hline $\begin{array}{l}\text { Rodovia } \\
\text { Rodovia }\end{array}$ & - & $\begin{array}{l}\text { Manutenção e Sinalização da Malha Rodoviária } \\
\text { Manutenção e Sinalização da Malha Rodoviária }\end{array}$ & $\begin{array}{l}99.451,982 \\
23.531,294\end{array}$ & $\begin{array}{l}\text { Concluída } \\
\text { Em execução }\end{array}$ \\
\hline Rodovia & - & Manutenção e Sinalização da Malha Rodoviária & $\begin{array}{l}\text { Ação prepa- } \\
\text { ratória }\end{array}$ & Em execução \\
Rodovia & $\begin{array}{l}\text { Laranjal do Jari, } \\
\text { Macapá, Maza- } \\
\text { gão e Santana }\end{array}$ & $\begin{array}{l}\text { BR-156/AP - Pavimentação de Macapá ao Entron- } \\
\text { camento AP-031 (Eixo sul) }\end{array}$ & 896.300 \\
\hline $\begin{array}{l}\text { Usina Hidrelé- } \\
\text { trica }\end{array}$ & Laranjal do Jari & Construção da UHE Santo Antônio do Jari & 1.300 .000 & Concluída \\
\hline $\begin{array}{l}\text { Usina Hidrelé- } \\
\text { trica }\end{array}$ & Ferreira Gomes & Construção da UHE Ferreira Gomes & 812.000 & Concluída \\
\hline $\begin{array}{l}\text { Usina Hidrelé- } \\
\text { trica }\end{array}$ & Ferreira Gomes & Construção da UHE Cachoeira Caldeirão & 1.207 .350 & Concluída \\
\hline
\end{tabular}

*Valor total referente à execução da ação em 32 portos, em 16 unidades da federação.

Fonte: Brasil (2018b).

Organização e elaboração: Margarit, 2018.

O eixo da BR-156, de Macapá/Santana à Oiapoque concentra a maior parte dos investimentos, servindo à estratégia de formação de um eixo de desenvolvimento, conforme havia sido previsto desde a formulação dos Enid, em 1996. A constituição deste eixo permite a integração de uma parcela significativa do território do estado aos circuitos produtivos, já que a rodovia atravessa o estado de norte a sul e integra todas as cidades do estado, seja diretamente ao longo de seu eixo, ou indiretamente por meio de outras rodovias que são acessadas pela BR-156, como pode ser observado no Mapa 3.

Mapa 3: Obras do Pac no Amapá

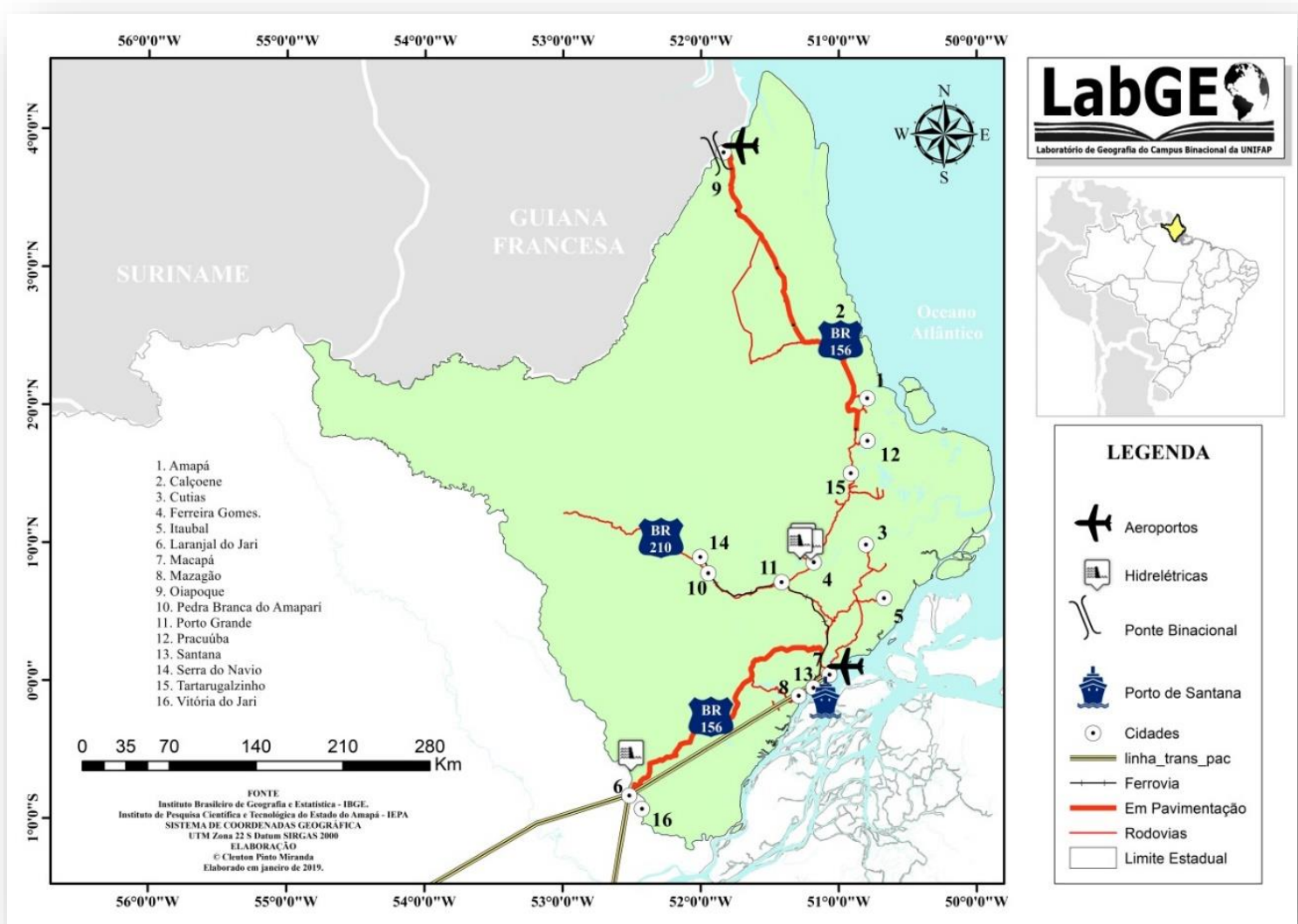

PRACS: Revista Eletrônica de Humanidades do Curso de Ciências Sociais da UNIFAP 
No núcleo urbano principal do estado (Macapá/Santana) estão as principais obras do Pac de conexão com o Brasil e o mundo. A estrutura portuária e aeroportuária servem para este fim e estão sendo reestruturadas para se adequar aos padrões exigidos pelo mercado internacional. A conectividade do Amapá com o Brasil e o mundo é o principal potencial de desenvolvimento do capitalismo que o estado possuí, mas é ao mesmo tempo o principal "gargalo" existente, pois a precária infraestrutura portuária e aeroportuária não permitem o pleno desenvolvimento de atividades logísticas em grandes volumes.

Para potencializar a atividade portuária e agregar maior competitividade estão sendo realizadas readequações no Porto de Santana. O Pac alocou investimentos para o projeto Porto Sem Papel (PSP), com o objetivo de implantar um concentrador de dados e um portal de informações portuárias para agilizar o transito de mercadorias nos portos, e o Programa Federal de Apoio a Regularização e Gestão Ambiental Portuária (PRGAP) (BRASIL, 2018). Há ainda a concessão para investimentos privados no porto por meio do Programa de Investimentos em Logística (PIL), que permite o arrendamento de áreas do Porto de Santana e a construção de terminais de uso privativo.

Segundo Viana (2016), o Porto de Santana estabelece relações com pelo menos outros 9 portos brasileiros e 18 portos estrangeiros, com fluxos de carga de minério de ferro, manganês, celulose, combustível, eucalipto, pinus, soja, trigo e contêineres, fruto de sua localização e condições singulares para o transporte flúvio-marítimo. Os arrendamentos e a reestruturação do Porto de Santana estão, respectivamente, permitindo investimentos privados e potencializando a sua capacidade de uso, tornando-o mais competitivo.

Por sua vez, o novo terminal de passageiros do Aeroporto Internacional de Macapá - Alberto Alcolumbre - aumentou a capacidade de passageiros $/ \mathrm{ano}^{3}$. Essa adequação permitiu o aumento da oferta de voos, que favorece as atividades empresariais e proporciona melhores condições de receptividade a turistas e empreendedores.

No tocante às rodovias, a pavimentação da BR-156 representa a fluidez territorial que conecta as cidades do Amapá e também as terras do cerrado, mais propícias ao desenvolvimento da agricultura. Os trechos não asfaltados da BR-156 tornam-se de difícil tráfego durante o rigoroso período de chuvas, devido a formação de atoleiros, portanto, a pavimentação asfáltica é fundamental para manter a trafegabilidade regular e com maior fluidez, questões essenciais para o pleno desenvolvimento das atividades capitalistas.

Por sua vez, a construção das usinas hidrelétricas previstas no Pac para o Amapá permitem a geração de energia de baixo custo para as atividades produtivas. No Rio Jari foi construída a UHE Santo Antônio do Jari (inaugurada em 2014) e no Rio Araguari foram construídas as hidrelétricas UHE Ferreira Gomes (inaugurada em 2015), a jusante da UHE Coaracy Nunes, e a UHE Cachoeira Caldeirão (inaugurada em 2016), a montante da UHE de Coaracy Nunes. A construção de novas usinas hidrelétricas no Amapá representam a introdução de grandes empreendimentos de apropriação dos bens naturais do estado, essencialmente do potencial hidrelétrico, e figuram como monumentos símbolos de desenvolvimento do poder hegemônico.

A construção de novas usinas hidrelétricas ocorreu não apenas para suprir a crescente demanda de energia do Amapá, mas também do restante do País, pois junto com a construção de novas usinas hidrelétricas foi realizada a construção de linhas de transmissão, conectando o Amapá ao Sistema Interligado Nacional (SIN). Com isso, tornou-se possível o envio e o recebimento de energia do Amapá para o restante do País, o que torna o fornecimento 
de energia elétrica mais estável para as unidades consumidoras. A maior estabilidade e confiabilidade do fornecimento de energia elétrica agregou competitividade ao território, atraindo empresas e investimentos privados.

O sistema de telecomunicações do Amapá também foi modernizado com a instalação de uma rede de fibra ótica. Essa rede é composta por cabos que interligam o Amapá à Guiana Francesa e ao Pará, este último por meio da infraestrutura de torres do Sin. Esta nova rede de fibra óptica permite a melhor conectividade dos sistemas de telecomunicações do Amapá, principalmente da internet. A melhoria dos sistemas de telecomunicações também é fator preponderante na agregação de competitividade ao território, na medida em que permite a melhor fluidez de informações digitais, requisito essencial para a instalação de diversos empreendimentos ligados à lógica do capitalismo mundial.

Já a ponte internacional sobre o rio Oiapoque estabelece a conexão entre a malha rodoviária do Amapá e da Guiana Francesa e, por extensão, com o Suriname e a Guiana. Tal fato possuí um caráter simbólico de aproximação das relações entre Brasil e França, entretanto, é importante ponderar que a criação de condições de tráfego rodoviário entre o Amapá e a Guiana Francesa é o caráter prático mais significativo deste projeto, que rompe definitivamente com a condição insular do transporte rodoviário do Amapá, oferecendo uma possibilidade repleta de oportunidades para empreendimentos capitalistas em ambos os estados (Amapá e Guiana Francesa).

A ponte passou a permitir o transito de pessoas e mercadorias entre os dois países e, com isso, potencializou atividades como o turismo e o comércio exterior, que gradativamente estão se intensificando. O potencial dessa nova condição de conectividade rodoviária entre o Amapá e a Guiana Francesa ainda não é plenamente explorado devido a dois entraves: o primeiro refere-se ao fato de que a BR-156 ainda não teve a pavimentação asfáltica conclú́da, o que impede a plena fluidez do tráfego entre o município de Oiapoque e o restante do estado; o segundo refere-se a acordos bilaterais, que impõem restrições ao transito de pessoas e mercadorias, principalmente por parte do governo francês, que exige visto para a entrada de brasileiros na Guiana Francesa.

Aos programas nacionais de desenvolvimento no Amapá somam-se os programas estaduais e, em menor grau, os programas municipais, que são desdobramentos do Pac. Trata-se de ações em menor escala, que atuam de forma complementar aos programas nacionais, como instrumento de capilaridade das redes técnicas desenvolvidas pelo Pac, potencializando e dilatando a fluidez e a competitividade territorial. Foi sob este contexto que o Governo do Estado do Amapá lançou, em 2010, um plano rodoviário, que prevê a pavimentação asfáltica de diversas rodovias no Amapá (GEA, 2016).

Há ainda obras do Pac restritas à outras unidades da federação que contribuem para o processo de reordenamento territorial pelo capitalismo no Amapá. Uma das principais obras de infraestrutura que está proporcionando a integração do Amapá aos circuitos produtivos ocorre no estado vizinho, o Pará. O Pac incluiu o asfaltamento da BR-163 (CuiabáSantarém) em suas metas ${ }^{4}$. A pavimentação da BR-163 está integrando a produção de grãos do estado de Mato Grosso aos portos da Região Norte, proporcionando maior competitividade à soja produzida no Mato Grosso, pela redução de custos com frete, e incorporando novas terras à produção no estado do Pará.

Este aproveitamento do potencial logístico dos portos da Região Norte inseriu o Amapá no circuito produtivo do agronegócio, já que parte da soja produzida no estado do Mato

PRACS: Revista Eletrônica de Humanidades do Curso de Ciências Sociais da UNIFAP 
Grosso passou a ser exportada por meio do Porto de Santana (Porto Organizado da CDSA), por meio do transbordo da soja de balsas para os navios ${ }^{5}$. Portanto, o desenvolvimento do agronegócio de grãos no Amapá é consequência da inserção da infraestrutura logística de exportação de grãos do Mato Grosso, que viabilizou a produção também no Amapá, a partir do aproveitamento do sistema graneleiro implantado no Porto de Santana.

\section{CONSIDERAÇÕES FINAIS}

O Pac foi resultante de um processo de planejamento territorial da Amazônia no contexto do capitalismo global, consolidando a infraestrutura que vem sendo planejada para a região desde a década de 1970. Se com o governo de Jair Bolsonaro o Pac foi definitivamente abandonado enquanto plataforma de desenvolvimento, o mesmo não ocorreu com os seus projetos, que continuaram sendo executados com o título simplesmente de "obras do Governo Federal".

No Amapá, assim como em toda a Amazônia, o aproveitamento do potencial logísticolocalizacional e bens naturais pelo capitalismo depende da criação de redes técnicas capazes de gerar a fluidez necessária para a integração territorial competitiva aos circuitos produtivos do capitalismo global. Diante do modelo de desenvolvimento adotado pelo Estado e sua materialização na expansão da fronteira capitalista, fruto da constituição das redes técnicas, o Amapá figura neste cenário como fronteira contemporânea. Sua condição de isolamento das redes técnicas da Região Centro-Sul durante o século XX é rescindida gradativamente com as grandes obras de infraestrutura do Pac, como usinas hidrelétricas, linhas de transmissão, pavimentação de rodovias e a reestruturação do aparelho portuário e aeroportuário.

Portanto, as grandes obras de infraestrutura no Amapá significam a consolidação de redes técnicas em parâmetros mínimos necessários ao desenvolvimento de empreendimentos do grande capital. Nesse cenário, o Governo do Estado do Amapá vem sendo responsável pela adoção de medidas complementares às estratégias do Governo Federal, alternando entre momentos de maior e menor intensidade de sintonia das políticas territoriais, mas sempre com algum nível de complementariedade. Tem sido assim que o Governo do Estado do Amapá tem agido, principalmente, na pavimentação de rodovias estaduais, capilarizando a infraestrutura de circulação implantada pelo Governo Federal.

A geração de energia firme e barata, a disponibilidade de rodovias em boas condições de tráfego e infraestrutura portuária e aeroportuária competitivas são algumas das prerrogativas requeridas pelos empreendimentos capitalistas para que possam se instalar no estado e produzirem em condições capazes de permitir a inserção competitiva no mercado interno e externo. Estas prerrogativas são sinalizadas como imperativos para o desenvolvimento econômico, mas também são instrumentos do processo de ordenamento territorial em curso no Amapá, centralizando em torno das redes técnicas os empreendimentos do grande capital.

\section{Notas}

1 Pesquisa financiada pela Coordenação de Aperfeiçoamento de Pessoal de Nível Superior (Capes) (2016-2018).

2 Termo que designa um grito de guerra na língua dos indígenas da etnia Kaiapó (MANCHETE, 1989; RAMBO, 2014).

3 Não foram encontrados dados quantitativos confiáveis sobre a diferença de capacidade do

PRACS: Revista Eletrônica de Humanidades do Curso de Ciências Sociais da UNIFAP https://periodicos.unifap.br/index.php/pracs 
antigo e do novo terminal aeroportuário de Macapá, mas estima-se que seja da ordem de cinco vezes a capacidade do atual terminal.

4 O Pac prevê o asfaltamento de cerca de mil quilômetros da rodovia BR-163 entre Guarantã do Norte, no estado do Mato Grosso, e Santarém, no estado do Pará. Esta obra e suas consequências territoriais foram abordadas por Margarit (2017).

5 Sobre o assunto foi publicado o artigo intitulado Integração do Amapá ao circuito produtivo da soja, disponível em: < http://www.periodicoseletronicos.ufma.br/index.php/interes $\mathrm{paco} /$ article/view/6908>.

\section{REFERÊNCIAS}

BECKER, Bertha Koiffmann. Amazônia: Geopolítica na virada do III milênio. Rio de Janeiro, Garamond, 2004.

BRASIL. Ministério do Planejamento. PAC. Disponível em : <http://www.pac.gov.br/>. Acesso em : 30 jan. 2018.

GEA, Governo do Estado do Amapá. Plano Rodoviário avança com obra da AP-010. 21 jul. 2016. Disponível em: <https://www.portal.ap.gov.br/ler_noticia.php?slug=2907/planorodoviario-avanca-com-obra-da-ap-010>. Acesso em: 06 jan. 2019.

JARDIM, Maria Chaves; SILVA, Márcio Rogério. Programa de aceleração do crescimento (PAC): neodesenvolvimentismo? São Paulo: Editora UNESP/Cultura Acadêmica, 2015.

MANCHETE. Rio de Janeiro: Bloch Editores, n. 1.925, 11 mar. 1989.

MARGARIT. Eduardo. Fronteira agrícola na Amazônia: capitalismo e circuitos produtivos. Curitiba: Appris, 2017.

RAMBO, Rodrigo. Índia Tuíra. 11 set. 2014. Disponível em: < https://kararao.wordpress. com/2014/09/11/india-tuira/>. Acesso em: 30 dez. 2018.

SILVA, Ana Regina Ferreira da. Perspectivas das politicas territoriais na faixa de fronteira internacional da Amazônia Oriental brasileira: estados do Pará e do Amapá. Rio de Janeiro: Publit, 2012.

SUPERTI, Eliane. As fronteiras internacionais da Amazônia brasileira no contexto das políticas públicas de integração sul-americana. In: PORTO, Jadson Luís Rebelo; NASCIMENTO, Durbens M. (Org.). Dinâmicas periférico-estratégicas da fronteira da Amazônia setentrional: das políticas públicas e redes institucionais à integração espacial. Rio de Janeiro: Publit, 2013. p. 91-109.

VIANA, Telma Maria da Silva. Planejamento e gestão urbanos na orla fluvial de Santana: aportes para o desenvolvimento local. 2016. 222 f. Dissertação (Mestrado em Desenvolvimento Regional) Universidade federal do Amapá. 